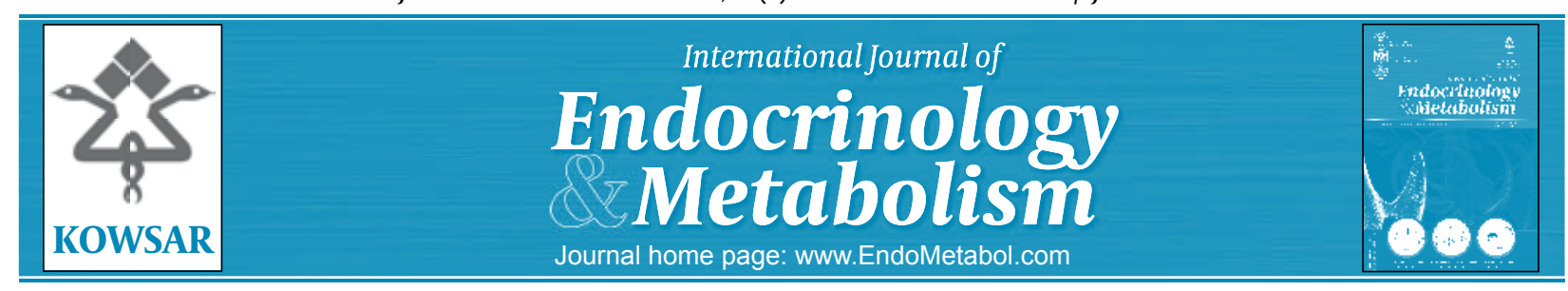

\title{
140 Cases of Macroprolactinemia: Selected Clinical and Technical Laboratory Aspects
}

\author{
Wojciech Jeske ${ }^{1^{*}}$, Piotr Glinicki ${ }^{1}$, Renata Kapuscinska ${ }^{1}$, Wojciech Zgliczynski ${ }^{1}$ \\ ${ }^{1}$ Department of Endocrinology, The Medical Centre of Postgraduate Education, Warsaw, Poland
}

\begin{tabular}{l}
\hline A R T I C L E I N F O \\
\hline Article type: \\
Original Article \\
\hline Article history: \\
Received: 22 Nov 2011 \\
Revised: 05 Dec 2011 \\
Accepted: 20 Dec 2011 \\
\hline
\end{tabular}

Keywords:

Macroprolactin

Prolactin

\begin{abstract}
A B S T R A C T
Background: Macroprolactinemia can be an overlooked cause of hyperprolactinemia. To document the presence of macroprolactin in serum indirectly, an initial precipitation of the complexed prolactin (PRL) using polyethylene glycol (PEG) is followed by measurement of free and total prolactin by immunoassay.

Objectives: Adaptation of the PEG method to our PRL immunoassay to detect cases with predominant macroprolactinemia and to study the short- and long-term changes of the relationship between PRL forms.

Patients and Methods: One hundred forty hyperprolactinemic patients (aged 17-72 years) in whom macroprolactin constituted $\geq 60 \%$ of the total PRL were included in our study. The predominance of macroprolactin was measured by adapted PEG procedure, followed by immunoradiometric and chemiluminescence methods.

Long-term observations with repeated serum PRL measurements were made in 20 cases. For another 20 of 41 patients with indications for metoclopramide (MCP) stimulation test, we analyzed short-term alterations in free and complexed PRL levels.

Results: Adjustment of the PEG method by testing samples in dilution minimized the interference of PEG in the immunoassays and let proper detection of predominant macroprolactinemia. During the long-term observations, the ratio of macroprolactin to total PRL remained relatively constant, independent of changes in total PRL levels. During the MCP test, in the majority of patients with macroprolactinemia (except those with associated PRL-secreting adenoma), an acute rise of PRL level followed by a rise in macroprolactin resulted in a short-term decrease in macroprolactin/total PRL ratio.

Conclusions: Confirmation of the predominance in serum of macroprolactin explains the discordance between the raised PRL level and scant of absent symptoms characteristic for hyperprolactinemia. Its proper detection can influence further management.
\end{abstract}

Copyright $\odot 2012$ Kowsar M. P. Co. All rights reserved.

- Implication for health policy/practice/research/medical education:

Macroprolactinemia can be an overlooked cause of hyperprolactinemia and this may lead to misdiagnosis and mismanagement. Therefore proper detection of macroprolactin is important for clinical practice.

Please cite this paper as:

Jeske W, Glinicki P, Kapuscinska R, Zgliczynski W. 140 cases of Macroprolactinemia: Selected Clinical and Technical Laboratory Aspects, Poland. Int J Endocrinol Metabol. 2012;10(1):394-8. DOI: 10.5812/ijem.3600

* Corresponding author: Wojciech Jeske, Department of Endocrinology, Medical Centre of Postgraduate Education Ceglowska 80, 01-809 Warsaw, Poland. Tel:+48-225690293, Fax:+48-228343131, E-mail: jeske.wojciech@gmail.com

DOI: $10.5812 /$ ijem.3600

Copyright $\odot 2012$ Kowsar M. P. Co. All rights reserved.

\section{Background}

Nearly 20 years has passed since the fully evidenced cases of macroprolactinemia were reported by Hattori $e t$ al. $(1,2)$. According to Hattori (1), the first such case was described 11 years earlier by Whittaker et al. (3), likely the first to introduce the term "Big-Big PRL" (BB-PRL). During the last 20 years, many original reports, reviews, and comments on this topic have been published in medical 
journals of which some selected earlier examples can be cited (4-12).

In general, macroprolactin is defined as a complex of monomeric prolactin with anti-PRL IgG. Due to macroprolactin high molecular mass, its bioavailability and bioactivity are decreased, which, with its reduced clearance, may account for the persistence of hyperprolactinemia $(7,12)$. Despite numerous publications (4-12), our understanding of the macroprolactin problem is still poor, and BB-PRL measurement methods are not broadly accessible (13). The most frequently used procedure for the routine evaluation of the meaningful predominance of macroprolactin in serum is a simple and rapid method of precipitation of the complexed PRL using $25 \%$ polyethylene glycol (PEG), followed by the measurement of the free PRL fraction in the supernatant after centrifugation of the precipitated bound PRL fraction and the total PRL in untreated serum. It is generally accepted that a recovery of PRL in the post-PEG supernatant sample of $\leq 40 \%$ reflects the predominance of BB-PRL $(6,7,10-13)$.

\section{Objectives}

The aim of our study was to adapt PEG precipitation method to our immunoassays to detect patients with predominant macroprolactinemia among those with hyperprolactinemia and examine the short- and long-term changes in the relationship between PRL forms. To study the short-term changes in total, free, and complexed prolactin levels, the metoclopramide (MCP) stimulation test was appropriate. Metoclopramide (a dopamine receptor antagonist) is useful for testing prolactin secretory reserves, which is usually excessive in patients with functional hyperprolactinemia. In contrast, the response to MCP is markedly diminished or absent in patients with an autonomous PRL-secreting pituitary adenoma $(6,8,12)$.

\section{Patients and Methods}

Of 175 detected cases with predominant macroprolactinemia, we obtained sufficient data for 140 subjects for inclusion into our study. Of these 140 patients, there were 136 females and 4 males (aged 17-72 years). The majority of our hyperprolactinemic patients was investigated for the presence of BB-PRL, because they were either asymptomatic or poorly symptomatic in relation to PRL levels. In 41 of 140 cases, with indications for initial testing of PRL secretory reserve, the oral metoclopramide (MCP) stimulation test was performed, in 20 of whom we analyzed short-term alterations in total, free, and complexed PRL levels, induced by $10 \mathrm{mg}$ MCP administered orally. MRI or CT imaging was usually performed in patients in whom the PRL level was higher than $100 \mu \mathrm{g} / \mathrm{L}$ and sometimes with a PRL of 50-100 $\mu \mathrm{g} / \mathrm{L}$ if there were other reasons to do so. Twenty patients were investigated for the presence of BB-PRL during a longer observation period, ranging from 6 to 120 months (median length 36 months). To precipitate the complexed PRL in serum, we used 25\% polyethylene glycol (PEG-6000, Fluka W/V), and after vigorous vortexing, followed by centrifugation for 15 minutes at $3000 \mathrm{rpm}$ (1500 g), the appropriate dilutions of post-PEG supernatant and untreated serum were made in a zero calibrator or a designated PRL solvent. Both PRL measurements (the total and free PRL) were made at the same final dilution (x10) and in the same run, initially by immunoradiometric methods (PRL-IRMA, CIS, France and PRL-IRMA, Immunotech, France) and later by chemiluminescence (CLIA) on an Immulite 2000 (Siemens, Germany). The sensitivity of the IRMA assays was $0.65 \mu \mathrm{g} / \mathrm{L}$, the range of calibrators was 0.5-180 $\mu \mathrm{g} / \mathrm{L}$, and the intra- and inter-CV \% was $3-5 \%$ and $6-10 \%$, respectively. Same data for the PRL CLIA Immulite 2000 were: $0.5 \mu \mathrm{g} / \mathrm{L}, 0.5-150 \mu \mathrm{g} / \mathrm{L}, 2.8-3.3 \%$ and 4.0-5.3\%, respectively.

\section{Results}

Among 140 hyperprolactinemic patients with predominant macroprolactinemia, we noted 7 with pituitary hypertrophy and 6 with pituitary adenoma; the remaining 127 patients were diagnosed with idiopathic hyperprolactinemia. The presence or absence of specific clinical symptoms of hyperprolactinemia is presented in Table 1. The total and free PRL concentrations (range, median, and Mean $\pm S D$ ), the calculated percentages of BB-PRL, and the ranges of the observed responses to MCP stimulation (expressed as percentage in relation to basal level) are presented in Table 2.

Table 1. The incidence of Symptoms Characteristic for Hyperprolactinaemia in 3 Groups of Patients With Predominant Macroprolactinemia

\begin{tabular}{lcccc}
\hline & Quantity & Absent & Mild & Present \\
\hline $\begin{array}{l}\text { Idiopathic hyperpro- } \\
\text { lactinaemia }\end{array}$ & 127 & 96 & 24 & 7 \\
Pituitary hypertrophy & 7 & 6 & 1 & 0 \\
Pituitary adenoma & 6 & 1 & 2 & 3 \\
\hline
\end{tabular}

Table 2. The Total and Free PRL Concentrations, and the Calculated Percent of BB-PRL, as Well as the Response to MCP Stimulation in 3 Groups of Patients With Predominant Macroprolactinemia

\begin{tabular}{lllll}
\hline & \multicolumn{2}{l}{ PRL Conc., $\mu \mathbf{g} / \mathbf{L}$} & & \\
\cline { 2 - 3 } Diagnosis & Total & Free & $\begin{array}{l}\text { Calculated } \\
\text { BB-PRL, \% }\end{array}$ & $\begin{array}{l}\text { Response to MCP } \\
\text { stimulation, \% }\end{array}$ \\
\hline $\mathrm{IH}^{\mathrm{a}},(\mathrm{n}=127)$ & & & & \\
range & $26-305$ & $0.2-34$ & $60-100$ & $210-960$ \\
Mean \pm SD & $78 \pm 45$ & $9 \pm 7$ & $85 \pm 12$ & 313 \\
Median & 62 & 8 & 87 & 255 \\
PH $^{\mathrm{a}},(\mathrm{n}=7)$ & & & & \\
Range & $57-220$ & $1-11$ & $92-100$ & $200-295$ \\
Mean & 125 & 7 & 96 & 250 \\
PA ${ }^{\mathrm{a}},(\mathrm{n}=6)$ & & & & \\
Range & $70-700$ & $4-75$ & $86-94$ & $11-30$ \\
Mean & 310 & 31 & 90 & 15 \\
\hline
\end{tabular}

a Abbreviations: IH , Idiopathic Hyperprolactinaemia; PH, Pituitary Hypertrophy, PA, Pituitary Adenoma 
In long term-observations in 20 patients (Tables 3,4 ), the percentage ratio of BB-PRL remained stable despite the moderate changes in total PRL concentration that were caused by the treatment with dopamine agonists or cessation of this treatment, This ratio was not stable during pregnancy.

\begin{tabular}{|c|c|c|c|c|}
\hline $\begin{array}{l}\text { Patient } \\
\text { No., Age, y }\end{array}$ & $\begin{array}{l}\text { Month of } \\
\text { Blood Col- } \\
\text { lection }\end{array}$ & $\begin{array}{l}\text { Total PRL } \\
\text { Conc., } \\
\mu \mathrm{g} / \mathbf{L} \\
\end{array}$ & $\begin{array}{l}\text { Free PRL } \\
\text { Conc. , } \\
\mu \mathrm{g} / \mathbf{L}\end{array}$ & BB-PRL, \% \\
\hline \multirow[t]{3}{*}{1,48} & 0 & 134 & 10 & 93 \\
\hline & 12 & 68 & 9 & 87 \\
\hline & 20 & 62 & 10 & 84 \\
\hline \multirow[t]{4}{*}{2,23} & 0 & 128 & 7 & 95 \\
\hline & 12 & 36 & 1,7 & 96 \\
\hline & 24 & 112 & 3,7 & 97 \\
\hline & 36 & 120 & 4 & 97 \\
\hline \multirow[t]{3}{*}{3,42} & 0 & 71 & 18 & 75 \\
\hline & 12 & 83 & 7 & 92 \\
\hline & 23 & 55 & 5 & 90 \\
\hline \multirow[t]{4}{*}{4,28} & 0 & 110 & 10 & 91 \\
\hline & 12 & 130 & 7 & 95 \\
\hline & 36 & 56 & 4 & 93 \\
\hline & 44 & 60 & 4 & 93 \\
\hline \multirow[t]{6}{*}{5,43} & 0 & 91 & 26 & 72 \\
\hline & 16 & 59 & 13 & 78 \\
\hline & 36 & 47 & 6 & 87 \\
\hline & 66 & 92 & 23 & 75 \\
\hline & 90 & 45 & 5 & 89 \\
\hline & 120 & 40 & 7 & 82 \\
\hline \multirow[t]{3}{*}{6,27} & 0 & 44 & 8 & 82 \\
\hline & 33 & 33 & 6 & 82 \\
\hline & 44 & 60 & 4 & 93 \\
\hline \multirow[t]{4}{*}{7,24} & 0 & 110 & 1,5 & 100 \\
\hline & $19^{a}$ & 290 & 52 & 82 \\
\hline & 44 & 103 & 3 & 97 \\
\hline & 50 & 85 & 1 & 99 \\
\hline \multirow[t]{3}{*}{8,27} & 0 & 235 & 21 & 91 \\
\hline & 54 & 21 & 0,2 & 90 \\
\hline & 66 & 32 & 2 & 94 \\
\hline \multirow[t]{2}{*}{9,42} & 0 & 83 & 7 & 92 \\
\hline & 6 & 50 & 6 & 88 \\
\hline \multirow[t]{3}{*}{10,36} & 0 & 36 & 10 & 72 \\
\hline & 44 & 41 & 11 & 73 \\
\hline & 74 & 39 & 6 & 85 \\
\hline \multirow[t]{2}{*}{11,30} & 0 & 50 & 8 & 84 \\
\hline & 10 & 47 & 8 & 83 \\
\hline \multirow[t]{2}{*}{12,46} & 0 & 136 & 34 & 75 \\
\hline & 10 & 42 & 16 & 62 \\
\hline \multirow[t]{3}{*}{13,41} & 0 & 86 & 32 & 63 \\
\hline & 24 & 73 & 1 & 86 \\
\hline & 36 & 76 & 1 & 87 \\
\hline \multirow[t]{2}{*}{14,45} & 0 & 120 & 3 & 97 \\
\hline & 16 & 100 & 3 & 97 \\
\hline \multirow[t]{3}{*}{15,36} & 0 & 70 & 17 & 76 \\
\hline & 32 & 120 & 17 & 86 \\
\hline & 36 & 130 & 17 & 87 \\
\hline
\end{tabular}

\footnotetext{
a During: P, Pregnancy
}

Table 4. Serum PRL Concentrations (Total \& Free) With the Calculated Percentage of BB-PRL in 5 Patients With Pituitary Adenoma and Concomitant Predominant Macroprolactinemia Measured During Long-Term Observation Lasting 6-72 Months, While Being on or Off Treatment.

\begin{tabular}{|c|c|c|c|c|}
\hline $\begin{array}{l}\text { Patient } \\
\text { No., Age, y }\end{array}$ & $\begin{array}{l}\text { Month of } \\
\text { Blood Col- } \\
\text { lection }\end{array}$ & $\begin{array}{l}\text { Total PRL } \\
\text { Conc. } \\
\mu \mathrm{g} / \mathrm{L}\end{array}$ & $\begin{array}{l}\text { Free PRL } \\
\text { Conc. } \\
\mu \mathrm{g} / \mathrm{L}\end{array}$ & $\begin{array}{l}\text { BB-PRL, } \\
\%\end{array}$ \\
\hline \multicolumn{5}{|l|}{ Female } \\
\hline \multirow[t]{4}{*}{1,30} & 0 & 540 & 50 & 91 \\
\hline & $19^{a}$ & 510 & 75 & 85 \\
\hline & 28 & 250 & 25 & 90 \\
\hline & 43 & 40 & 4 & 90 \\
\hline \multirow[t]{5}{*}{2,32} & 0 & 700 & 75 & 89 \\
\hline & $18^{a}$ & 247 & 45 & 82 \\
\hline & 42 & 58 & 5 & 91 \\
\hline & $62^{a}$ & 280 & 100 & 64 \\
\hline & 72 & 41 & 1 & 97 \\
\hline \multirow[t]{6}{*}{3,25} & 0 & 130 & 38 & 71 \\
\hline & 16 & 115 & 14 & 88 \\
\hline & 36 & 132 & 14 & 89 \\
\hline & 48 & 130 & 12 & 90 \\
\hline & 60 & 120 & 14 & 88 \\
\hline & 70 & 240 & 40 & 83 \\
\hline \multicolumn{5}{|l|}{ Male } \\
\hline \multirow[t]{2}{*}{4,21} & 0 & 100 & 4 & 96 \\
\hline & 17 & 76 & 3 & 96 \\
\hline \multirow[t]{2}{*}{5,72} & 0 & 70 & 4 & 94 \\
\hline & 6 & 25 & 1 & 96 \\
\hline
\end{tabular}

${ }^{\text {a During: Pregnancy }}$

\section{Discussion}

Macroprolactinemia can be an overlooked cause of hyperprolactinemia, primarily because a significant portion of patients with predominant macroprolactinemia do not present symptoms that are commonly associated with hyperprolactinemia. Therefore, such a situation may lead to misdiagnosis and mismanagement $(8,10,14)$. We must also be aware that macroprolactinemia can be associated with other causes of hyperprolactinemia, such as pituitary adenoma and pituitary hypertrophy, and although such coincidence happens rarely, it warrants special attention and full diagnostic workup (7, 11, 14-18),. The special attention concers mainly patients who, in addition to predominant macroprolactinemia, have significantly elevated free PRL. In our experience and those of other groups, a lack of or a markedly decreased response to stimulation with metoclopramide (MCP) in patients with high basal levels of PRL may be indicative of autonomous PRL-secreting pituitary adenoma $(6,8,12,17)$, On the other hand, the majority of patients with predominant BB-PRL shows regular or excessive responses to stimulation with MCP, similar to patients with idiopathic hyperprolactinemia and those who present with pituitary hypertrophy (9). Like other groups, we were able to show that in patients with BB-PRL, MCP caused an initial acute rise in free PRL levels, followed by a slower rise in BB-PRL (4, $6,15)$. Further, in 20 patients who were observed for longer periods (ranging from 6 to 120 months), the ratio of BB-PRL to total PRL remained constant, despite marked changes in 


\begin{tabular}{|c|c|c|c|c|}
\hline $\begin{array}{l}\text { Patient } \\
\text { No., Age, y }\end{array}$ & $\begin{array}{l}\text { MCP Test } \\
\text { Time, min }\end{array}$ & $\begin{array}{l}\text { Total PRL } \\
\text { Conc., } \mu \mathrm{g} / \mathbf{L}\end{array}$ & $\begin{array}{l}\text { Free PRI } \\
\text { Conc. } \mu g / L\end{array}$ & BB - PRL, \% \\
\hline \multirow[t]{3}{*}{1,46} & 0 & 136 & 34 & 75 \\
\hline & 60 & 410 & 200 & 52 \\
\hline & 120 & 320 & 130 & 60 \\
\hline \multirow[t]{3}{*}{2,48} & 0 & 68 & 9 & 87 \\
\hline & 60 & 200 & 60 & 70 \\
\hline & 120 & 150 & 34 & 78 \\
\hline \multirow[t]{3}{*}{3,40} & 0 & 50 & 8 & 84 \\
\hline & 60 & 133 & 66 & 50 \\
\hline & 120 & 120 & 42 & 65 \\
\hline \multirow[t]{3}{*}{4,38} & 0 & 74 & 6 & 92 \\
\hline & 60 & 160 & 52 & 67 \\
\hline & 120 & 147 & 42 & 72 \\
\hline \multirow[t]{3}{*}{5,57} & 0 & 62 & 0 & 100 \\
\hline & 60 & 107 & 44 & 41 \\
\hline & 120 & 98 & 43 & 44 \\
\hline \multirow[t]{2}{*}{6,24} & 0 & 110 & 1,5 & 99 \\
\hline & 60 & 250 & 95 & 62 \\
\hline \multirow[t]{2}{*}{7,23} & 0 & 92 & 7 & 93 \\
\hline & 60 & 238 & 77 & 68 \\
\hline \multirow[t]{2}{*}{8,43} & 0 & 91 & 26 & 72 \\
\hline & 60 & 237 & 200 & 16 \\
\hline \multirow[t]{2}{*}{9,28} & 0 & 116 & 10 & 92 \\
\hline & 60 & 264 & 117 & 56 \\
\hline \multirow[t]{2}{*}{10,42} & 0 & 71 & 18 & 75 \\
\hline & 60 & 146 & 93 & 37 \\
\hline \multirow[t]{2}{*}{11,40} & 0 & 55 & 8 & 86 \\
\hline & 60 & 220 & 80 & 64 \\
\hline \multirow[t]{2}{*}{12,48} & 0 & 51 & 10 & 72 \\
\hline & 60 & 170 & 99 & 21 \\
\hline \multirow[t]{2}{*}{ 13., 35} & 0 & 36 & 10 & 80 \\
\hline & 60 & 232 & 184 & 42 \\
\hline \multirow[t]{2}{*}{14,22} & 0 & 103 & 12 & 88 \\
\hline & 60 & 200 & 60 & 70 \\
\hline \multirow[t]{2}{*}{15,24} & 0 & 63 & 1,5 & 98 \\
\hline & 60 & 180 & 100 & 45 \\
\hline \multirow[t]{2}{*}{16,30} & 0 & 61 & 7 & 89 \\
\hline & 60 & 300 & 90 & 70 \\
\hline \multirow[t]{2}{*}{17,28} & 0 & 67 & 13 & 81 \\
\hline & 60 & 200 & 100 & 50 \\
\hline \multirow[t]{2}{*}{18,33} & 0 & 27 & 11 & 60 \\
\hline & 60 & 180 & 100 & 45 \\
\hline \multirow[t]{2}{*}{19,38} & 0 & 60 & 1,2 & 98 \\
\hline & 60 & 196 & 52 & 73 \\
\hline \multirow[t]{2}{*}{20,27} & 0 & 32 & 6 & 82 \\
\hline & 60 & 120 & 40 & 67 \\
\hline
\end{tabular}

total PRL concentrations, caused by treatment with dopamine agonists or cessation of this treatment. Similar results were recently reported by Hattori et al. (19). An important methodological problem in evaluating patients with macroprolactinemia is that methods of PRL estimation have variable degrees of reactivity with BB-PRL, and in some cases, the difference in outcome is 2.7-7.2-fold (20). Therefore, each laboratory should examine this matter, determine whether the presence of anti-PRL in serum causes any distortion in its PRL assay, and adapt the method of separating free from complexed PRL to be compatible with the immunoassay. The classical method, gel filtration chromatography (GFC), is time-consuming and too expensive for routine use. Therefore, the most widely used technique has become measuring PRL recovery after serum BB-PRL precipitation with polyethylene glycol. This method, which initially was proposed to detect insulin autoantibodies (2), has been validated by other groups $(6,10,11,20-23)$. It appears that this PEG method, although it is not specific or quantitative, shows the best correlation with GFC (22, 23). Difficulties in BB-PRL measurements arise with the variable influence of the final (12.5\%) PEG concentration in the sample on the immunological reaction in immunoassay systems $(7,15,21)$. Therefore, some groups that have used the PRL-IRMA assay have proposed treating all calibrators and control samples with $25 \%$ PEG solution. Such a procedure is not convenient and is not applicable for automatic platforms. For the IRMA assay, we propose performing both PRL measurements (total and free PRL) in the 10-times final dilution prepared in the zero calibrator $(9,17)$; in the case of automatic methods, such dilutions can be made in the appropriate diluent for each immunoassay platform. In our opinion, diluting samples with PBS or distilled water may cause greater distortions between the PRL result in undiluted samples and the recalculated result of the measurement in diluted samples due to the matrix effect. This could explain why Beltram et al. (21) did not recommend routine dilution of samples, although it decreases PEG interference. Parallel testing of free and total PRL in diluted samples was introduced recently by Hattori et al.(19). Centrifugal ultrafiltration, proposed by Prazeres et al., is a potentially useful method for separating high-molecular-mass forms of PRL (24). This method, defined on physical principles, should not interfere in the PRL assay system and could be useful in assays in which such interference of PEG was noted (13). In practice, however, according to Gibney et al. (7) and Kavanagh et al. (22), this method can not be recommended as a suitably precise and reliable method for routine use.

The PEG method remains the most useful technique for indirectly measuring the presence of BB-PRL as the predominant form of serum prolactin, but its routine use should be tested for compatibility with a particular PRL immunoassay. Confirmation of the predominance of BB-PRL explains the common discordance between increased PRL levels and scant or absent symptoms that are characteristic for hyperprolactinemia. Incidental coexistence of macroprolactinemia and pituitary adenoma or pituitary hypertrophy 
demands special attention, thus, full diagnostic procedures should be undertaken, including the MCP stimulation test.

During the oral MCP test, an acute rise in free PRL levels, followed by a slower rise in BB-PRL, resulted in a short-term decrease in BB-PRL/total PRL ratio in the majority of patients with macroprolactinemia (except those with the associated PRL-secreting adenoma). During long-term observation, the BB-PRL/total PRL ratio remains relatively constant, independent of changes in total PRL levels that are induced by the specific treatment or its cessation.

\section{Acknowledgements}

None declared.

\section{Financial Disclosure}

None declared.

\section{Funding/Support}

CMKP grant No. 501-1-08-21/03 \& 501-1-08-11/11

\section{References}

1. Hattori N, Ikekubo K, Ishihara T, Moridera K, Hino M, Kurahachi $\mathrm{H}$. A normal ovulatory woman with hyperprolactinemia: presence of anti-prolactin autoantibody and the regulation of prolactin secretion. Acta Endocrinol (Copenh). 1992;126 (6) :497-500.

2. Hattori N, Ishihara T, Ikekubo K, Moridera K, Hino M, Kurahach H. Autoantibody to human prolactin in patients with idiopathic hyperprolactinemia. J Clin Endocrinol Metab. 1992;75 (5) :1226-9.

3. Whittaker PG, Wilcox T, Lind T. Maintained fertility in a patient with hyperprolactinemia due to big, big prolactin.J Clin Endocrinol Metab. 1981;53 (4):863-6.

4. Bjoro T, Johansen E, Frey HH, Turter A, Torjesen PA. Different responses in little and bigbig prolactin to metoclopramide in subjects with hyperprolactinemia due to $150-170 \mathrm{kD}$ (bigbig) prolactin. Acta Endocrinol (Copenh). 1993;128 (4):308-12.

5. Bjoro T, Morkrid L, Wergeland R, Turter A, Kvistborg A, Sand T, et al. Frequency of hyperprolactinaemia due to large molecular weight prolactin (150-170 kD PRL). Scand J Clin Lab Invest. 1995;55 (2) :139-47.

6. Fahie-Wilson MN, Soule SG. Macroprolactinaemia: contribution to hyperprolactinaemia in a district general hospital and evaluation of a screening test based on precipitation with polyethylene glycol. Ann Clin Biochem. 1997;34 ( Pt 3) :252-8.

7. Gibney J, Smith TP, McKenna TJ. Clinical relevance of macroprolactin. Clin Endocrinol (Oxf). 2005;62 (6):633-43.

8. Hattori N, Ikekubo K, Ishihara T, Moridera K, Hino M, Kurahachi $\mathrm{H}$. Correlation of the antibody titers with serum prolactin levels and their clinical course in patients with anti-prolactin autoantibody. EurJ Endocrinol. 1994;130 (5) :438-45.
9. Jeske W, Zgliczynski W, Gorzelak K. [Macroprolactin in subjects with hyperprolactinaemia: clinical observations and relations between free PRL and PRL complexed with IgG]. Endokrynol Pol. 2005;56 (5): :779-84.

10. Leslie H, Courtney CH, Bell PM, Hadden DR, McCance DR, Ellis PK, et al. Laboratory and clinical experience in 55 patients with macroprolactinemia identified by a simple polyethylene glycol precipitation method. J Clin Endocrinol Metab. 2001;86 (6) :27436.

11. Olukoga AO, Kane JW. Macroprolactinaemia: validation and application of the polyethylene glycol precipitation test and clinical characterization of the condition. Clin Endocrinol (Oxf). 1999;51 (1) :119-26.

12. Vallette-Kasic S, Morange-Ramos I, Selim A, Gunz G, Morange S, Enjalbert A, et al. Macroprolactinemia revisited: a study on 106 patients. J Clin Endocrinol Metab. 2002;87 (2):581-8.

13. Sadideen $\mathrm{H}$, Swaminathan R. Macroprolactin: what is it and what is its importance? Int J Clin Pract. 2006;60 (4):457-61.

14. Donadio F, Barbieri A, Angioni R, Mantovani G, Beck-Peccoz P, Spada A, et al. Patients with macroprolactinaemia: clinical and radiological features. Eur J Clin Invest. 2007;37 (7) :552-7.

15. Gibney J, Smith TP, McKenna TJ. The impact on clinical practice of routine screening for macroprolactin. J Clin Endocrinol Metab. 2005;90 (7) :3927-32.

16. Hauache OM, Rocha AJ, Maia AC, Jr., Maciel RM, Vieira JG. Screening for macroprolactinaemia and pituitary imaging studies. Clin Endocrinol (Oxf). 2002;57 (3) :327-31.

17. Jeske W, Zgliczynski W, Zdunowski P. Laboratory and clinical experience in 55 patients with macroprolactinemia identified by a simple polyethylene glycol precipitation method. J Clin Endocrinol Metab. 2002;87 (4):1909-10; author reply 10.

18. Strachan MW, Teoh WL, Don-Wauchope AC, Seth J, Stoddart M, Beckett GJ. Clinical and radiological features of patients with macroprolactinaemia. Clin Endocrinol (Oxf). 2003;59 (3) :339-46.

19. Hattori N, Ishihara T, Saiki Y, Shimatsu A. Macroprolactinaemia in patients with hyperprolactinaemia: composition of macroprolactin and stability during long-term follow-up. Clin Endocrinol (Oxf). 2010;73 (6) :792-7.

20. Smith TP, Suliman AM, Fahie-Wilson MN, McKenna TJ. Gross variability in the detection of prolactin in sera containing big big prolactin (macroprolactin) by commercial immunoassays.J Clin Endocrinol Metab. 2002;87 (12):5410-5.

21. Beltran L, Fahie-Wilson MN, McKenna TJ, Kavanagh L, Smith TP. Serum total prolactin and monomeric prolactin reference intervals determined by precipitation with polyethylene glycol: evaluation and validation on common immunoassay platforms. Clin Chem. 2008;54 (10) :1673-81.

22. Kavanagh L, McKenna TJ, Fahie-Wilson MN, Gibney J, Smith TP. Specificity and clinical utility of methods for the detection of macroprolactin. Clin Chem. 2006;52 (7):1366-72.

23. McCudden CR, Sharpless JL, Grenache DG. Comparison of multiple methods for identification of hyperprolactinemia in the presence of macroprolactin. Clin Chim Acta. 2010;411 (3-4) :15560.

24. Prazeres S, Santos MA, Ferreira HG, Sobrinho LG. A practical method for the detection of macroprolactinaemia using ultrafiltration. Clin Endocrinol (Oxf). 2003;58 (6) :686-90. 